\title{
A EFETIVIDADE DA LEI DE LICITAÇÕES NOS MUNICÍPIOS MARANHENSES NO PERÍODO DE 2010 A 2013
}

\section{THE EFFECTIVITY OF THE BIDDINGS LAW IN THE MARANHENSES MUNICIPALITIES DURING PERIOD OF 2010 TO 2013}

\author{
Vinicius Costa do Vale Correa ${ }^{1}$, José Washington de Freitas Diniz Filho ${ }^{2}$
}

RESUMO: A licitação é o procedimento administrativo utilizado pelos gestores públicos para adquirir bens, obras e serviços, objetivando identificar a proposta mais vantajosa para o Poder Público e garantir que todos os participantes tenham a mesma oportunidade de serem selecionados dentre aqueles que pretendem contratar com a Administração Pública. Sendo assim, o presente trabalho tem como objetivo principal verificar o comportamento das prestações de contas dos municípios maranhenses no período de 2010 a 2013, através das publicações de reprovações de contas públicas municipais no site do Tribunal de Contas do Estado do Maranhão (TCE/MA), e verificar o comportamento do grau de efetividade da lei de licitações nas prestações de contas dos municípios maranhenses. Para isso, serão utilizados procedimentos estatísticos sobre prestação de contas que foram reprovadas pelo Tribunal de Contas do Estado do Maranhão no período proposto. Nos resultados, constatou-se que o principal motivo de reprovações de contas municipais maranhenses é a desobediência aos mandamentos da Lei 8.666/93 por parte dos gestores públicos municipais e que o grau de efetividade da lei de licitações foi considerado relativo em nosso estudo.

PALAVRAS-CHAVE: Grau de efetividade. Licitações. Reprovação de contas públicas.

ABSTRACT: The bidding is the administrative procedure used by public managers to acquire goods, works and services, objectifying to identify the most advantageous proposal for the Public Power and to ensure that all participants have the same opportunity of being selected among those who intend to contract with the Public Administration. Therefore, the present work has as main objective to verify the behavior of the accountability of Maranhão municipalities during period of 2010 to 2013, through the publications of disapprovals of municipal public accounts on the site of the Maranhão State Court of Auditors (TCE/MA), and to verify the behavior of the degree of effectivity of the biddings law on the accountability of Maranhão municipalities. Thereunto, will be used statistical procedures about accountability that were disapproved by the Maranhão State Court of Auditors in the period proposed. In the results it was found that the main motive for reproving Maranhenses municipal accounts is the disobedience to the commandments of the Law 8,666/93 for the part of the municipal public managers and that the degree of effectivity of the biddings law was considered relative in our study.

KEYWORDS: Degree of Effectivity. Biddings. Reproving of Public Accounts.

\section{INTRODUÇÃO}

A Administração Pública tem uma grande demanda por bens e serviços de qualidade, objetivando atender o bem-estar social de forma eficiente, eficaz e com o máximo de economicidade possível. Para isso, utiliza-se de um mecanismo, o qual o Estado criou, e ao longo do tempo, vem aperfeiçoando para possibilitar ao gestor público o desprendimento mais eficiente do dinheiro público, denominado de licitação. Contudo, existem elementos humanos dentro dos entes governamentais que se utilizam deste mecanismo para cometerem desvio de finalidade dos recursos públicos.

${ }^{1}$ Graduado do curso de Ciências Contábeis da Universidade CEUMA. E-mail: viniciuscosta_correa@hotmail.com

${ }^{2}$ Mestre em Administração pela UFSM e Professor do curso de Ciências Contábeis da Universidade CEUMA.

E-mail: jwfdf@hotmail.com 
Conforme entendimento de Silva (2011), o procedimento licitatório objetiva identificar a proposta mais vantajosa para a Administração Pública e selecioná-la. Além disso, a licitação possibilita que todos os participantes tenham a mesma oportunidade de serem selecionados dentre aqueles que desejam contratar com o setor público e permite que seja feita a melhor escolha dentre o universo de fornecedores, objetivando evitar o favorecimento desse ou daquele participante.

Além do mais, percebe-se que, segundo Filho (2010), através do procedimento licitatório, o qual se encontra doutrinado pela lei 8.666/93, todos os princípios constitucionais atinentes à Administração Pública, como legalidade, impessoalidade, moralidade, publicidade e eficiência são materializados no normativo licitatório. Portanto, necessário se torna que o procedimento licitatório esteja sempre vinculado à lei, atendendo ao princípio da legalidade.

É importante lembrar que todo gestor público possui obrigações com a sociedade que o elegeu. Para isso, o procedimento licitatório é um meio administrativo que o poder público utiliza para obter e adquirir bens, obras e serviços indispensáveis ao atendimento dessas obrigações (OBSERVATÓRIO DE GESTÃO PÚBLICA DE LONDRINA, 2012).

Diante do exposto, a presente pesquisa pretende equacionar a seguinte problemática: qual o grau da efetividade da lei de licitações nas prestações de contas dos municípios maranhenses?

Cabe acrescentar, conforme lembra Liberato (2013), que as fraudes em licitações são consideradas uma das maiores moléstias dentro do setor público nacional, principalmente na esfera municipal, uma vez que é mais frequente esse tipo de conduta, pois a fiscalização e a devida repressão pelos órgãos de controle, muitas vezes, são insuficientes.

Observa-se ainda que além das fraudes licitatórias irem de encontro aos princípios da moralidade, lisura e idoneidade, elementos mínimos e necessários a todo agente público, as mesmas promovem um grave comprometimento dos recursos públicos nacionais, os quais, ao invés de serem destinados a setores estratégicos como a saúde e a educação, são desviados para setores de menor importância social para poderem atender a interesses escusos de poucos.

Freitas (2011) acrescenta ainda que, durante muito tempo, em uma boa parte dos estados brasileiros, houve a formação de oligarquias que se aproveitaram da burocracia e da dificuldade de fiscalização popular para se apoderarem dos órgãos estatais para garantirem seus interesses particulares.

Sendo assim, o objetivo principal deste trabalho é analisar o comportamento das prestações de contas dos municípios maranhenses no período de 2010 a 2013, através de investigações no site do Tribunal de Contas do Estado do Maranhão (TCE/MA), e verificar o comportamento da aplicabilidade da lei de licitações nas prestações de contas dos municípios maranhenses. Para isso, serão utilizados procedimentos estatísticos sobre prestação de contas que foram reprovadas pelo Tribunal de Contas do Estado do Maranhão no período proposto.

Estudos apontam (SILVA, 2011 e LIBERATO, 2013) que o superfaturamento de preços é o tipo de fraude mais comum dentro da Administração Pública com relação ao procedimento licitatório. Essa prática de comprometimento das contas públicas vem acompanhada do direcionamento, dispensa da licitação e ainda de acordo prévio entre os concorrentes. Outra prática irregular observada no processo de contratação por parte do setor público ocorre quando o edital da licitação não é publicado no Diário Oficial do ente governamental.

Outro tipo de dilapidação do patrimônio público que pode ser constatado no setor público com bastante frequência é a utilização de inexigibilidade de licitação. Esse procedimento de contratação por parte da Administração Pública é caracterizado quando não há possibilidade de competição, pois existe somente um prestador do serviço e um fornecedor do produto exclusivamente. Essa prática consiste no direcionamento e superfaturamento por parte do agente público de forma ilegal (LIBERATO, 2013).

Portanto, um maior rigor na fiscalização nas contratações e nas compras por parte do Estado aponta a importância desse estudo, pois com esse comportamento, há a possibilidade de uma maior maximização na alocação das verbas públicas, já que promoverá um direcionamento mais acertado desses recursos para setores sociais que convivem com grande deficiência desse elemento, 
como por exemplo, a educação e a saúde, e, consequentemente, estimular uma redução progressiva da carga tributária nacional.

Além disso, o presente trabalho está estruturado em quatro seções, além desta introdução. $\mathrm{Na}$ segunda, é apresentado o referencial teórico. $\mathrm{Na}$ terceira, os procedimentos metodológicos utilizados. Na quarta, a análise dos resultados que foram encontrados na pesquisa e, por fim, na última seção apresentam-se as principais conclusões do trabalho.

\section{METODOLOGIA}

\subsection{Enquadramento Metodológico}

O presente trabalho caracteriza-se por ser do tipo descritivo, já que se dispõe a verificar o grau de obediência dos municípios maranhenses aos mandamentos da lei 8.666/93 no período de 2010 até 2013.

Esse tipo de pesquisa, conforme GIL (2008), objetiva descrever a característica de determinada população ou fenômeno ou o estabelecimento da relação entre variáveis.

Além disso, o método de pesquisa utilizada apresenta uma abordagem quantitativa, pois será utilizado instrumental estatístico na análise dos dados.

Para Silveira e Córdova (2009), a pesquisa quantitativa, que tem suas raízes no pensamento positivista lógico, tende a enfatizar o raciocínio dedutivo, as regras da lógica e os atributos mensuráveis da experiência humana.

Quanto ao delineamento, o estudo desenvolveu-se em bases bibliográficas, já que ocorreu a partir do levantamento de referências teóricas já analisadas e publicadas. Além disso, a pesquisa está utilizando como embasamento para suas conclusões base documental, através de uma base de dados secundária colhida em publicações no site do Tribunal de Contas do Estado do Maranhão (TCE/MA). Conforme Cevo e Bervian (1996), a pesquisa bibliográfica tem como pressuposto a utilização de livros, periódicos, jornais e documentos específicos, objetivando buscar elucidar a temática em estudo.

\subsection{Coleta dos dados e definição dos parâmetros de medida para identificar o grau de efetividade da Lei de Licitações}

O estado do Maranhão está localizado na região Nordeste do Brasil, conforme Instituto Brasileiro de Geografia e Estatística (IBGE) e é composto por 217 municípios.

Os dados utilizados na pesquisa foram obtidos através das notícias publicadas no site do Tribunal de Contas do Estado do Maranhão (TCE/MA). Esse procedimento consistiu no levantamento de todas as notícias veiculadas sobre reprovação de contas públicas dos municípios do estado do Maranhão no período de 2010 até 2013. Cabe destacar que não foram utilizados na pesquisa períodos a partir de 2014, pois essas prestações de contas ainda estão em fase de julgamento por parte do tribunal.

Das 217 prestações de contas entregues pelos gestores públicos em cada ano, realizou-se a separação das contas que tinham sido reprovadas por motivos de desobediência à lei no 8.666/93 das prestações de contas que foram desaprovadas por outros motivos que não envolviam práticas licitatórias, objetivando identificar o comportamento da efetividade da lei 8.666/93 nas prestações de contas dos municípios maranhenses no período proposto. Das prestações de contas que haviam sido desaprovadas por falhas licitatórias, foi destacado o artigo que teve maiores reincidências de reprovações, o que teve menores reincidências e o que teve repetições intermediárias.

Para medir o grau de efetividade da lei de licitações, a pesquisa vale-se de quatro parâmetros de medidas: o primeiro parâmetro, denominado de alto grau de efetividade, se o índice de reprovações por motivos de falhas licitatórias for abaixo de 5\%; o segundo parâmetro, 
denominado de grau de efetividade provável, caso o índice de reprovações por motivos licitatórios for entre $5 \%$ e 50\%; o terceiro parâmetro, denominado de grau de efetividade relativa, se o índice de reprovações por motivos licitatórios for entre $50 \%$ e $95 \%$; e o quarto parâmetro, denominado de grau de efetividade remota, caso o índice de reprovações por motivos licitatórios seja acima de $95 \%$.

\section{RESULTADOS E DISCUSSÃO}

\subsection{Comportamento das reprovações de prestações de contas dos municípios maranhenses no período de 2010 até 2013}

Conforme se pode observar no gráfico 01, num primeiro momento, observa-se um comportamento decrescente em valores relativos de 19,13\% no número de reprovações de prestações de contas dos municípios maranhenses no período de 2010 até 2012.

Justifica-se esse comportamento devido ao Registro de 115 reprovações em 2010 dentre 217 prestações de contas entregues nesse ano, o que nos informa um índice de reprovação de aproximadamente $53 \%$ das contas públicas maranhenses no ano.

Em 2011, foi constatada 105 reprovações de prestações de contas do total de 217 municípios, o que demonstra um total $48,38 \%$ de índice de reprovação de prestação de contas. Cabe informar, que se pôde constatar também uma queda de 8,7\% nas reprovações de contas na passagem do exercício financeiro 2010 para 2011.

Já em 2012, foram registradas 93 contas reprovadas pelo TCE/MA, dentre 217 prestações de contas entregues nesse ano, evidenciando um índice de reprovações de prestações de contas no valor de 42,86\%. Além disso, foi encontrado comportamento semelhante no declínio das reprovações de contas públicas maranhenses na passagem do ano de 2011 para 2012, com o registro de $11,43 \%$.

Num segundo momento, contudo, a partir do exercício financeiro de 2012, constata-se um crescimento abrupto no número de reprovações das prestações de contas das prefeituras maranhenses por parte do TCE/MA.

Em 2012, das 217 prestações de contas entregues, 125 prefeituras tiveram suas contas reprovadas, o que demonstra um índice de reprovação de contas públicas maranhenses na importância de 57,60\%. Cabe apontar também que, na passagem do exercício financeiro de 2012 para o de 2013, constatou-se um crescimento de 34,40\% no número de reprovações de contas públicas, comportamento contrário encontrado nos exercícios anteriores.

Gráfico 01: Comportamento das reprovações de contas dos municípios maranhenses no período de 2010 a 2013.

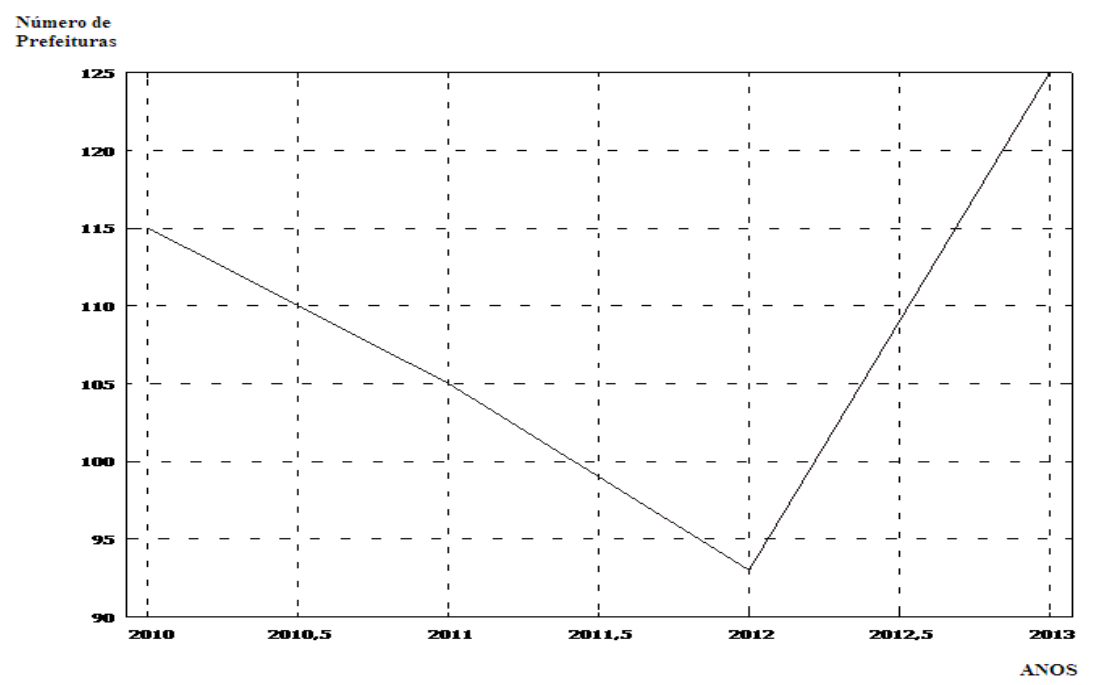

Fonte: Gráfico elaborado pelos autores. 


\subsection{Análise da efetividade da Lei $\mathbf{n}^{0} \mathbf{8 . 6 6 6 / 9 3}$ na prestação de contas dos municípios maranhenses}

Depois de realizada análise do comportamento das reprovações das prestações de contas dos municípios maranhenses pelo TCE/MA no período de 2010 até 2013, verifica-se agora o comportamento da efetividade da lei $\mathrm{n}^{\mathrm{o}} 8.666 / 93$ nas prestações de contas maranhenses nos anos de 2010, 2011, 2012 e 2013.

Logo, pode-se observar na tabela 01, que das 217 prestações de contas apresentadas ao TCE/MA, 115 foram reprovadas em 2010, significando uma marca de 53\% de índice de reprovação. Dessas 115 reprovações registradas, 50 foram referentes a outros motivos, o que representa $43,48 \%$ do total de prestações de contas reprovadas e 65 foram reprovadas por motivos ligados a desobediência à lei $\mathrm{n}^{\circ} 8.666 / 93$, registrando a marca de 56,52\% desse total. Isso indica, conforme definição dos parâmetros para medir o grau de efetividade apontados na metodologia do trabalho, um grau de efetividade relativa, pois está apresentando valores relativos entre $50 \%$ e $95 \%$.

Além disso, dos dispositivos da lei desrespeitados em 2010, o artigo 21 foi o que registrou maior ocorrência, com o número de 35 prestações de contas reprovadas por esse motivo. Em valores relativos representa $54 \%$ do número total de reprovações.

Por sua vez, o artigo 23 da lei $n^{\circ} 8.666 / 93$ foi que apresentou quantidade intermediária de motivos causadores da reprovação de prestação de contas dos municípios maranhenses, representando $31 \%$ das prestações de contas reprovadas por falhas licitatórias.

Por fim, o artigo 27 foi o que apresentou o menor nível de ocorrências motivadoras para a reprovação de contas públicas por desrespeito à lei de licitações, com apenas 15\% de ocorrências.

Tabela 01: Comportamento da efetividade da lei $n^{\circ} 8.666 / 93$ no exercício financeiro de 2010

\begin{tabular}{c|c|c|c}
\hline Total de Prestações de Contas & $\begin{array}{c}\text { Total de Prestações de } \\
\text { Contas Reprovadas }\end{array}$ & $\begin{array}{c}\text { Reprovação Por Outros } \\
\text { Motivos }\end{array}$ & $\begin{array}{c}\text { Reprovação Por } \\
\text { Licitação }\end{array}$ \\
\hline 217 & 115 & 50 & 65 \\
\hline $100 \%$ & $53 \%$ & $43,48 \%$ & $\mathbf{5 6 , 5 2 \%}$ \\
\hline $\begin{array}{c}\text { Artigos da lei no8.666/93 } \\
\text { infringidos }\end{array}$ & $\begin{array}{c}\text { Maior Quantitativo } \\
\text { Art. 21 }\end{array}$ & $\begin{array}{c}\text { Quantitativo Intermediário } \\
\text { Art. 23 }\end{array}$ & $\begin{array}{c}\text { Menor Quantitativo } \\
\text { Art. 27 }\end{array}$ \\
\hline $\begin{array}{c}\text { Quantidade de prestações de } \\
\text { contas reprovadas por esse } \\
\text { motivo }\end{array}$ & 35 & 20 & 10 \\
\hline Valores relativos & $54 \%$ & $31 \%$ & $15 \%$ \\
\hline
\end{tabular}

Fonte: Tabela elaborada pelos autores.

Continuando a análise da efetividade da lei de licitações nas prestações de contas dos municípios maranhenses, observa-se no ano de 2011, conforme a tabela 02, que do total de prestações de contas apreciadas pelo TCE/MA, 105 foram consideradas reprovadas, o que indica um índice de reprovação de contas de 48,39\%. Desse total, 70 foram reprovadas por apresentarem incompatibilidade com a lei $\mathrm{n}^{\circ} 8.666 / 93$, representando $66,66 \%$, o que demonstra a continuidade de um grau de efetividade de obediência da lei de licitações relativa, enquanto 35 prestações foram desaprovadas por outros motivos, evidenciando valores relativos de 33,33\%.

Do total de 70 prestações de contas que foram condenadas pelo TCE/MA por estarem em desacordo com a legislação licitatória, 39 municípios tiveram suas contas reprovadas por desobediência ao artigo 30 do normativo, o que representa 56\% do total; 25 prefeituras tiveram suas contas indeferidas por estarem em desacordo com o artigo 24 dessa lei, apresentando a marca de $36 \%$ do total de reprovações por motivos de licitações; e apenas 06 prefeituras, do total de 70 contas 
reprovadas, foram reprovadas suas contas por estarem em confronto com o artigo 23 da lei $\mathrm{n}^{\mathrm{o}} 8.666 / 93$, o que marca o registro de $9 \%$ do total.

Tabela 02: Comportamento da efetividade da lei $n^{\circ} 8.666 / 93$ no exercício financeiro de 2011

\begin{tabular}{c|c|c|c}
\hline Total de Prestações de Contas & $\begin{array}{c}\text { Total de Prestações de } \\
\text { Contas Reprovadas }\end{array}$ & $\begin{array}{c}\text { Reprovação Por Outros } \\
\text { Motivos }\end{array}$ & $\begin{array}{c}\text { Reprovação Por } \\
\text { Licitação }\end{array}$ \\
\hline 217 & 105 & 35 & 70 \\
\hline $100 \%$ & $48,39 \%$ & $33,33 \%$ & $\mathbf{6 6 , 6 6 \%}$ \\
\hline $\begin{array}{c}\text { Artigos da lei 8.666/93 } \\
\text { infringidos }\end{array}$ & $\begin{array}{c}\text { Maior Quantitativo } \\
\text { Art. 30 }\end{array}$ & $\begin{array}{c}\text { Quantitativo Intermediário } \\
\text { Art. 24 }\end{array}$ & $\begin{array}{c}\text { Menor Quantitativo } \\
\text { Art. 23 }\end{array}$ \\
\hline $\begin{array}{c}\text { Quantidade de prestações de } \\
\text { contas reprovadas por esse } \\
\text { motivo }\end{array}$ & 39 & & 06 \\
\hline Valores relativos & $56 \%$ & $36 \%$ & $9 \%$ \\
\hline
\end{tabular}

Fonte: Tabela elaborada pelos autores.

Dando prosseguimento a análise, agora no exercício financeiro de 2012, constata-se, observando a tabela 03, que do total de prestações de contas entregues ao TEC/MA, 93 municípios tiveram suas contas reprovadas nesse ano, representando um índice de reprovação no valor de 42,86\%. Desse total, 50 prefeituras tiveram suas contas rechaçadas por motivos de descaso licitatório, representando relativamente o valor de $53,76 \%$ e evidenciando um grau de efetividade relativa da lei 8.666/93. Por sua vez, 43 prestações de contas foram reprovadas por outros motivos, cuja representatividade é de $46,24 \%$.

Do total de 50 prestações de contas reprovadas por motivos licitatórios, constatou-se a ocorrência da desobediência ao artigo 21 da lei de licitações, sendo o maior quantitativo encontrado nesse exercício financeiro nos municípios maranhenses, representando uma importância de $50 \%$ dos motivos de reprovação por falhas licitatórias.

Por sua vez, os artigos 24 e 23 representaram quantitativo intermediário e menor quantitativo, respectivamente, com relação aos elementos motivadores para a desaprovação de contas públicas municipais no ano de 2012 , o que representou as marcas respectivas de $32 \%$ e $18 \%$ do total de contas reprovadas por motivos licitatórios.

Tabela 03: Comportamento da efetividade da lei nº.666/93 no exercício financeiro de 2012

\begin{tabular}{c|c|c|c}
\hline Total de Prestações de Contas & $\begin{array}{c}\text { Total de Prestações de } \\
\text { Contas Reprovadas }\end{array}$ & $\begin{array}{c}\text { Reprovação Por Outros } \\
\text { Motivos }\end{array}$ & $\begin{array}{c}\text { Reprovação Por } \\
\text { Licitação }\end{array}$ \\
\hline 217 & 93 & 43 & 50 \\
\hline $100 \%$ & $42,86 \%$ & $46,24 \%$ & $\mathbf{5 3 , 7 6 \%}$ \\
\hline $\begin{array}{c}\text { Artigos da lei no 8.666/93 } \\
\text { infringidos }\end{array}$ & $\begin{array}{c}\text { Maior Quantitativo } \\
\text { Art. 21 }\end{array}$ & $\begin{array}{c}\text { Quantitativo Intermediário } \\
\text { Art. 24 }\end{array}$ & $\begin{array}{c}\text { Menor Quantitativo } \\
\text { Art. 23 }\end{array}$ \\
\hline $\begin{array}{c}\text { Quantidade de prestações de } \\
\text { contas reprovadas por esse } \\
\text { motivo }\end{array}$ & 25 & 16 & 09 \\
\hline Valores relativos & $50 \%$ & $32 \%$ & $18 \%$ \\
\hline
\end{tabular}

Fonte: Tabela elaborada pelos autores.

Por fim, fazendo a análise do último ano proposto por esta pesquisa, observa-se na tabela 04 um crescimento abrupto no número de contas municipais reprovadas. Foi encontrado um valor de 125 contas reprovadas de um total de 217 contas prestadas, o que demonstra uma representatividade de $57,60 \%$ do total de contas. Desse total, 80 prestações foram consideradas incorretas pelo TCE/MA por motivos licitatórios, demonstrando um montante de $64 \%$ das contas municipais reprovadas, além de manter um grau de efetividade relativa da lei de licitações encontrado nos outros anos, e 45 prestações foram reprovadas por outros motivos (36\%).

Do total reprovado por motivação licitatória, 47 contas foram desaprovadas por infringirem o artigo 23 da lei 8.666/93, sendo o maior quantitativo encontrado, com uma representatividade de $58,75 \%$ do total. Por sua vez, os artigos 21 e 29 foram os que apresentaram representatividade 
intermediária e menor representatividade, já que mostraram valores absolutos de 25 e 08 prestações reprovadas por motivos de falha licitatória e valores relativos, respectivamente, de $31,25 \%$ e $10 \%$.

Tabela 04: Comportamento da efetividade da lei $n^{\circ} 8.666 / 93$ no exercício financeiro de 2013

\begin{tabular}{c|c|c|c}
\hline Total de Prestações de Contas & $\begin{array}{c}\text { Total de Prestações de } \\
\text { Contas Reprovadas }\end{array}$ & $\begin{array}{c}\text { Reprovação Por Outros } \\
\text { Motivos }\end{array}$ & $\begin{array}{c}\text { Reprovação Por } \\
\text { Licitação }\end{array}$ \\
\hline 217 & 125 & 45 & 80 \\
\hline $100 \%$ & $57,60 \%$ & $36 \%$ & $\mathbf{6 4 \%}$ \\
\hline $\begin{array}{c}\text { Artigos da Lei 8.666/93 } \\
\text { Infringidos }\end{array}$ & $\begin{array}{c}\text { Maior Quantitativo } \\
\text { Art. 23 }\end{array}$ & $\begin{array}{c}\text { Quantitativo Intermediário } \\
\text { Art. 21 }\end{array}$ & $\begin{array}{c}\text { Menor Quantitativo } \\
\text { Art. 29 }\end{array}$ \\
\hline $\begin{array}{c}\text { Quantidade de prestações de } \\
\text { contas reprovadas por esse } \\
\text { motivo }\end{array}$ & & & \\
\hline Valores relativos & 47 & 25 & 08 \\
\hline
\end{tabular}

Fonte: Tabela elaborada pelos autores.

Diante do exposto, pode-se afirmar, após observação dos resultados no gráfico 02 e os parâmetros definidos na metodologia para medir o grau de efetividade da lei de licitação, que em todos os anos do período proposto pela pesquisa o principal motivo para as reprovações das prestações de contas dos municípios maranhenses pelo TCE/MA foi a desobediência aos mandamentos da lei ${ }^{\circ} 8.666 / 93$, evidenciando o descaso por parte dos gestores públicos municipais maranhenses com esse normativo pátrio e evidenciando um grau de efetividade relativa da lei de licitações nas contas públicas do estado do Maranhão, pois os valores relativos das reprovações por motivos licitatórios flutuaram acima de $50 \%$ e abaixo de $95 \%$ em todos os anos.

Conforme se pode constatar no gráfico 02, existem dois movimentos ascendentes na linha que representa o comportamento das reprovações das contas públicas municipais maranhenses por problemas de licitação: na passagem do exercício financeiro de 2010 para 2011 e de 2012 para 2013, e apenas um momento de declínio em 2012 por esse motivo. Contudo, observa-se que em todo o período analisado, as reprovações por motivos de falhas licitatórias sempre superam os outros motivos de reprovações.

Gráfico 02: Comportamento das reprovações de contas dos municípios maranhenses por motivos de falha licitatória e por outros motivos no período de 2010 a 2013.

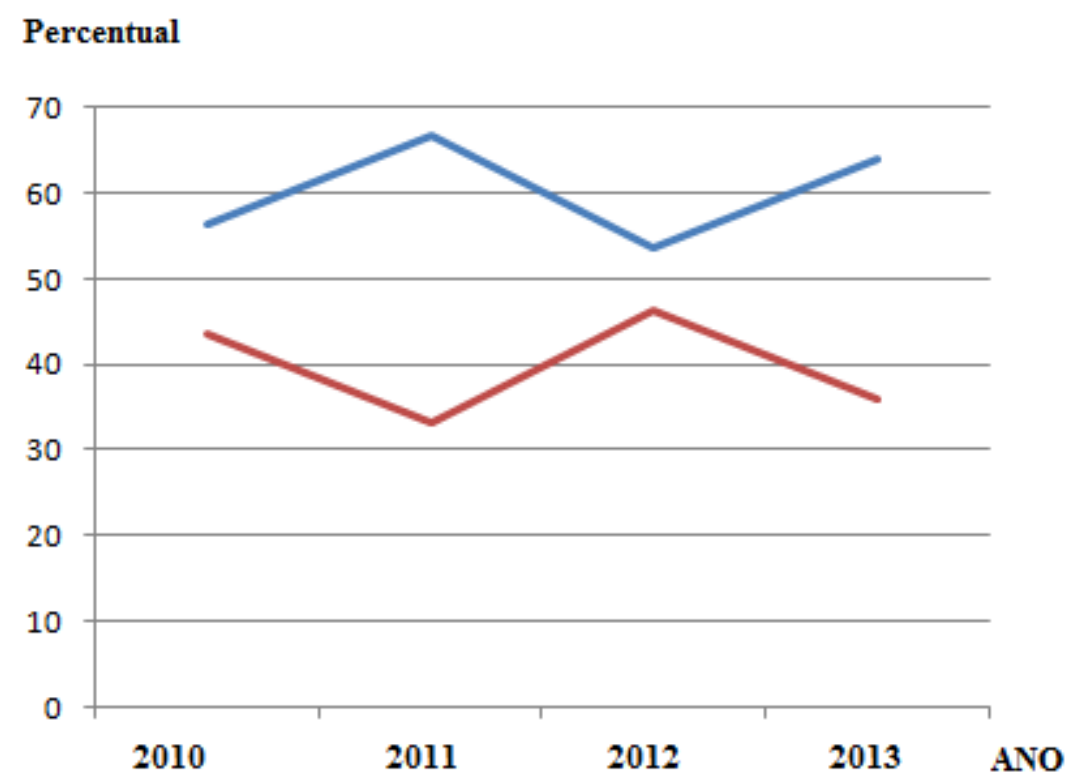

Fonte: Gráfico elaborado pelos autores. 
Além disso, é importante frisar que os artigos 21 e 23 da lei $n^{\circ} 8.666 / 93$ foram os que apresentaram maior reincidência nas reprovações de contas municipais do estado do Maranhão no período analisado, com destaque para o artigo 21, uma vez que atingiu a liderança em dois exercícios financeiros, no ano de 2010 e de 2012.

\section{CONCLUSÕES}

O setor público tem uma grande necessidade por bens e serviços de qualidade, objetivando atender o bem-estar social de forma eficiente, eficaz e com o máximo de economicidade possível. Para satisfazer essas necessidades, utiliza-se de uma ferramenta legislativa denominada de licitações, a qual objetiva selecionar a proposta mais vantajosa além de possibilitar que todos os participantes tenham a mesma possibilidade de terem suas propostas escolhidas pela Administração Pública.

Sendo assim, a presente pesquisa objetivou constatar o grau de efetividade que a lei 8.666/93 possui nas prestações de contas dos municípios maranhenses. Para isso, fez-se um levantamento de todas as prestações de contas que foram reprovadas no período de 2010 a 2013, através do site do Tribunal de Contas do Estado do Maranhão.

Num primeiro momento, após análise do comportamento do total das reprovações das contas municipais maranhenses observou-se que, no período de 2010 a 2012, houve um declínio no índice de reprovações de prestações de contas municipais, registrando os valores relativos de 53\%, 48,39\% e 42,86\% nos anos de 2010, 2011 e 2012, respectivamente. No ano de 2013, detectou-se um crescimento anormal no índice de reprovações total de contas municipais do estado do Maranhão. Do total de 217 prestações de contas entregues pelos gestores públicos, 125 foram consideradas reprovadas, apresentando um índice de reprovação de 57,60\%.

Num segundo momento, analisou-se o comportamento das reprovações só que agora por motivos de falhas licitatórias. Observou-se que, em todo o período proposto pela pesquisa, imperou as reprovações de contas públicas municipais do estado do Maranhão por motivos de desobediência da lei nº 8.666/93 em relação a outros motivos de reprovações, o que nos leva a concluir pelo descaso por parte dos gestores públicos a esse instrumento legislativo e por apresentar um grau de efetividade relativo desse normativo pátrio, já que os índices de reprovações por motivos licitatórios apresentaram valores relativos acima de $50 \%$ e inferior a $95 \%$.

Por fim, verificou-se o comportamento dos artigos da lei de licitações que estavam sendo desrespeitados pelos gestores públicos municipais e constatou-se no estudo que os artigos 21 e 23 foram os mais desobedecidos, com destaque especial para o artigo 21 já que, nos anos de 2010 e 2012, liderou os motivos de reprovações de contas dos municípios maranhenses.

\section{REFERÊNCIAS}

CERVO, A. L.; BERVIAN, P. A. Metodologia científica. 4 ed. São Paulo: Makron Books, 1996.

FILHO, V. A.. Importância das Licitações para Administração Pública. In: Juris Wai. Maio 2010. Disponível em: < http://www.jurisway.org.br/v2/dhall.asp?id_dh=4072 >. Acesso em 05 de abril de 2016.

FILHO, B. T.. LICITAÇÕES: Comentários, teoria e prática. Rio de Janeiro: Editora Forense, 1998.

FREITAS, D. B.. E-procurement governamental e o fim das antigas formas de licitações.

Disponível em: <http://www.egov.ufsc.br/portal/conteudo/e-procurement-governamental-e-o-fimdas-antigas-formas-de-licita\%C3\% A7\% C3\%B5es-licita\%C3\%A7\%C3\% A3o-eletr\%C3\%B4nicac>. Acesso em: 16 de junho de 2016. 
GIL, A. C.. Métodos e Pesquisa Social. São Paulo: Atlas, 2008

LIBERATO, C. dos S.. Fraudes em Licitações Públicas. In: Boletim Jurídico, n. 1118, Nov 2013. Disponível em: < http://www.boletimjuridico.com.br/m/texto.asp?id=2952>. Acesso em 05 de abril de 2016.

OBSERVATÓRIO DE GESTÃO PÚBLICA DE LONDRINA. O que é uma Licitação. Disponível em <http://observatoriolondrina.org.br/saiba-mais/o-que-e-licitacao.html>. Acesso em: 18 de maio de 2016.

SILVA, E. M. N.. Contratação direta na administração pública. In: Âmbito Jurídico, Rio Grande, XIV, n. 84, jan 2011.Disponível em: <http://www.ambitojuridico.com.br/site/index.php?n_link=revista_artigos_leitura\&artigo_id=8877>. Acesso em 07 de abril de 2016.

SILVEIRA, D. T.; CÓRDOVA, F. P.. Métodos de Pesquisa. Porto Alegre: Editora da UFRGS, 2009. 